\title{
Behavior of lactating Holstein-Friesian cows during spontaneous cycles of estrus
}

\author{
G. Sveberg, ${ }^{\star} \dagger^{1}$ A. O. Refsdal, ${ }^{*}$ H. W. Erhard, $¥ \S$ E. Kommisrud,\# M. Aldrin, $\|$ I. F. Tvete, $\|$ F. Buckley, $\|$ \\ A. Waldmann, ${ }^{\star *}$ and E. Ropstad† \\ *GENO Breeding and Al Association, N-2317 Hamar, Norway \\ †Department of Production Animals Clinical Sciences, Norwegian School of Veterinary Science, N-0033 Oslo, Norway \\ ¥AgroParisTech, 75005 Paris, France \\ §INRA, UMR 791 Modélisation Systémique Appliquée aux Ruminants, 75005 Paris, France \\ \#BioKapital AS, N-2317 Hamar, Norway \\ \|Norwegian Computing Center, N-0373 Oslo, Norway \\ TAnimal and Bioscience Research Department, Animal and Grassland Research and Innovation Centre, Teagasc, Moorepark, Fermoy, \\ Co. Cork, Ireland \\ **Department of Reproductive Biology, Institute of Veterinary Medicine and Animal Sciences, Estonian University of Life Sciences, \\ 51014 Tartu, Estonia
}

\section{ABSTRACT}

The objectives of the present study were to describe, in detail, behavior associated with standing estrus (STE) in lactating dairy cows and behavioral changes during complete estrous cycles. Estrus signs were monitored by continuous video recording of 20 Holstein-Friesian (HF) cows housed on an outdoor wood-chip pad during 1 estrous cycle $(22 \mathrm{~d})$. Other social behavior was recorded during STE and, for comparison, during 1 selected day when none of the cows were in estrus. Standing stationary when mounted was defined as the primary estrus sign. Anogenital sniff, chin rest, attempt to mount, and mount were defined as secondary estrus signs. Ovarian cyclicity was confirmed by progesterone measurements. This study reports short mean duration of STE $(7.1 \pm$ $1.44 \mathrm{~h}$ ) and estrus (mount period; $12.9 \pm 1.84 \mathrm{~h}$ ) of the 13 cows expressing these signs. All mounting activities involved at least one cow in, or within $4 \mathrm{~h}$ of, STE. The most frequent sign during STE was anogenital sniff initiated, followed by chin rest received, chin rest initiated, chase up initiated, anogenital sniff received, mount initiated, head butt, mount received, attempt to mount initiated, push away received, play rub, attempt to mount received, follow initiated, threat received, flehmen, avoid, bellow, and social lick received. Standing and mounting activity in HF cows was inconsistent during estrus, indicating that other signs could be of greater use. The frequency of secondary estrus signs initiated and received increased gradually during the last $12 \mathrm{~h}$ before STE, revealing significant differences between periods from 4 to 6 and 1 to $3 \mathrm{~h}$ before STE. A

Received June 28, 2010.

Accepted November 19, 2010.

${ }^{1}$ Corresponding author: guro.sveberg@geno.no considerable increase in receptive behavior (secondary estrus signs received) was identified between 1 to $3 \mathrm{~h}$ prior to STE and STE. Both frequent initiated and received behaviors were associated with STE. A significant decrease in the frequency of secondary estrus signs initiated and received occurred $3 \mathrm{~h}$ after STE. Cows in STE simultaneously predominantly chose the other standing cow as mate and expressed secondary estrus signs more frequently. Based on the results of this study, we suggest that chase up could be regarded as a reliable indicator of estrus and that the changes in proceptive (initiated) and receptive (received) behavior could be used as predictors of different stages in estrus. Knowledge of these behavioral signs may improve heat detection rates and the ability to predict the optimum breeding time for dairy cows.

Key words: estrous cycle, social behavior, standing estrus, secondary estrus sign

\section{INTRODUCTION}

Detection of estrus is a prerequisite for optimal timing of insemination. Standing estrus (STE), the period during which the cow makes no effort to escape when mounted, is the primary sign of true estrus (Hurnik et al., 1975). Time of ovulation and breeding can be predicted within a relatively narrow time window, based on the onset and cessation of standing or mounting activity (Stevenson et al., 1983; Roelofs et al., 2005). Reports in the literature of low frequencies of standing and mounting activity may explain low heat detection rates, despite frequent visual attention (Pennington et al., 1986; Lopez et al., 2004). Higher heat detection rates have been obtained by observing other signs associated with estrus (Van Eerdenburg et al., 1996).

Various physical and behavioral signs are involved, and determining the duration of estrus depends on the 
choice of signs and the method of observation. Hurnik et al. (1975) defined estrus as the interval between the first and the last mounting or mounted response. Thus, the term "estrus" generally covers a longer period than the more precise period of STE. Dransfield et al. (1998), using HeatWatch software (DDx Inc., Denver, $\mathrm{CO}$ ), classified STE as occurring when a cow had a minimum of 3 standing events in any 4 -h period. However, mount detectors are only able to detect received mounts and do not record the identity of the initiating cow. Few studies report differences in initiating and receiving behaviors during estrus (Pennington et al., 1986; Kerbrat and Disenhaus, 2004), but changes in behavioral strategies could be associated with specific stages in the estrous cycle. Thus, when comparing studies, differences in the definition of estrus and in the method of observation need to be considered.

The majority of studies conducted over the last decades have primarily focused on mounting behavior (Trimberger, 1948; Esslemont et al., 1980). Hurnik et al. (1975) described vulva sniffing and chin pressing (resting), but early studies did not regard chin resting as indicative of estrus (Foote, 1975). These signs, in addition to aggressive and mounting behaviors, were later quantified by Esslemont et al. (1980). However, as anogenital sniffing and chin resting also occur in other stages of the estrous cycle (Phillips and Schofield, 1990), the challenge for the observer is to determine whether a cow exhibiting this behavior is in STE. Although more recent papers report such behavior as a prominent sign of estrus (Van Eerdenburg et al., 1996; Kerbrat and Disenhaus, 2004), other social behaviors in cattle associated with estrus are not well documented (Mülleder et al., 2003; Kerbrat and Disenhaus, 2004).

Continuous surveillance by video or visual observation is the only way to obtain accurate data on the duration of estrus (Nebel et al., 2000) and can provide new background information for improved estrus detection in the field (Williamson et al., 1972). In studies using automated mounting devices or time-lapse observations, behavior associated with specific stages of the estrous cycle might be overlooked. Recent technological advances have made it possible to record and store large amounts of data collected during continuous video surveillance. This has provided new possibilities for detailed behavioral research.

A study by Esslemont and Bryant (1976) recorded mounting activity in detail through complete estrous cycles, but no recent continuous studies have described estrus signs during the complete estrous cycle of cows. The main objective of the present study was therefore to describe the behavior of Holstein-Friesian (HF) dairy cows during complete estrous cycles, using continuous video surveillance. Secondary objectives were to identify behavioral signs that could be predictive of STE and to assess whether changes in behavior could be used to predict specific estrus stages and serve as practical tools in visual heat detection.

\section{MATERIALS AND METHODS}

\section{Animals, Housing, and Management}

Twenty HF cows were housed on an outdoor pad from April 11 to May 16, 2006, at the Teagasc Moorepark Ballydague research farm in Ireland. The study duration was $22 \mathrm{~d}$, beginning on April 18. The pad was $17 \times 24 \mathrm{~m}$ with wood chip flooring (O'Driscoll et al., 2008). Cows were offered freshly harvested grass ad libitum twice daily, a flat rate allowance of $2.6 \mathrm{~kg}$ of concentrate DM per cow in the milking parlor, and unlimited access to fresh water. Cows were in first parity to sixth parity, with a frequency distribution of 8,3 , $2,4,2$, and 1 , respectively. Cows included in the study were at least 5 wk postpartum (mean $63 \mathrm{~d}$; range 44 to $84 \mathrm{~d}$ ), had no abnormal signs in the reproductive tract upon examination by ultrasound, had lameness scores of $\leq 2$ (Sprecher et al., 1997) and had BCS of at least 2.5 (Lowman et al., 1976).

The cows were milked twice daily (0700 and 1530 h), using a parallel milking stall with $2 \times 20$ milking places. Individual cow milk yield was recorded using electronic milk meters (Dairymaster, Causeway, Co. Kerry, Ireland). Reproductive organs were examined by ultrasound (Aloka SSD-500, Tokyo, Japan), equipped with a $5-\mathrm{MHz}$ rectal transducer, between d 28 and 35 , and $\mathrm{d} 50$ and 60 postpartum to reveal reproductive disorders and evidence for ovarian cyclicity. Body condition score was scored monthly postpartum and 14 d before start of the study. Body weights were recorded weekly.

\section{Ovarian Function}

A potassium dichromate preservative tablet (Lactab Mark III, Thompson \& Capper Ltd., Cheshire, UK) was immediately added to daily whole milk samples, which were then cooled, labeled, and frozen within 2 $\mathrm{h}$ at $-20^{\circ} \mathrm{C}$ until measurement of progesterone concentrations by enzyme immunoassay (Waldmann, 1993) modified by using the second antibody coating technique. The specificity of the monoclonal antibody 9C11 is described by Waldmann (1999). The interassay coefficients of variation for milk progesterone concentrations of 1.48 and $19.66 \mathrm{ng} / \mathrm{mL}$ were 9.21 and $5.32 \%$, respectively. The intraassay coefficient of variation was $<10 \%$. The sensitivity limit, using a $20-\mu \mathrm{L}$ milk sample, was $<0.5 \mathrm{ng} / \mathrm{mL}$. 
Function of the corpus luteum (cyclicity) was confirmed by progesterone profiling, characterized by successive waves of increasing and decreasing progesterone values. Standing estrus was confirmed by low milk progesterone concentrations $(<2.5 \mathrm{ng} / \mathrm{mL})$ during this period.

\section{Stages of the Estrous Cycle}

The definitions by Hurnik et al. (1975) were modified and used as follows. Standing estrus (true estrus) was defined as the interval between the first and last standing events, at which the cow makes no effort to escape when mounted by other cows. This interval may coincide with, or be shorter than, the mounting period.

Mounting estrus (estrus; mount period) was defined as the interval from the first to the last mount engaged in by the cow going through STE, or cyclic nonstanding cows with confirmed low progesterone concentrations during this period. A minimum of 2 mounts within 24 $\mathrm{h}$ were required.

Cows were observed continuously through 1 estrous cycle for a period of at least $21 \mathrm{~d}$, until all cows either had showed a regular cyclic change in progesterone concentrations and STE when progesterone was $<1$ $\mathrm{ng} / \mathrm{mL}$, or only a regular cyclic progesterone profile without STE. Behavioral observations were continued for $24 \mathrm{~h}$ after the last standing to be mounted observation of the last cow expressing STE, resulting in a total study period of $22 \mathrm{~d}$ of all cows. Records from $1 \mathrm{~d}$ of nonestrus, on which cows did not express STE, on neither the preceding nor the following day, and had progesterone levels of at least $2 \mathrm{ng} / \mathrm{mL}$ were used for comparisons within cows during STE and during nonestrus. The luteal phase was defined as the period between 7 and $16 \mathrm{~d}$ after the end of STE. For those cows whose study period was completed during the luteal phase, data from the previous estrous cycle, up to $4 \mathrm{~d}$ before estrus, were added. Thereby, data from an estimated luteal phase of $10 \mathrm{~d}$ duration was obtained for each cow. The periods $24 \mathrm{~h}$ before and after STE, STE, the $1 \mathrm{~d}$ of nonestrus, and the luteal phase of the estrous cycle were analyzed because the data did not reveal major changes in other phases of the cycle. The periods $24 \mathrm{~h}$ before and after STE were defined as the 24 $\mathrm{h}$ before the first standing event and the $24 \mathrm{~h}$ after the last standing event of STE, respectively. These periods were further divided into shorter 3-h intervals, because the major changes and visually detectable levels were reached within the last $6 \mathrm{~h}$ before STE and because 3 -h periods have been used in other recent studies of estrus signs (Roelofs et al., 2004)

\section{Behavior Recording and Data Management}

Two cameras (Axis 211, Axis Communications, Lund, Sweden), both covering the area of the paddock, were placed $3.5 \mathrm{~m}$ above the ground at one corner of the short ends of the rectangular pad. Individual identification codes were painted on the neck, flank, and upper leg of each cow to facilitate identification. To allow continuous video surveillance, artificial light was used at night.

Behavioral signs were used as defined here: (1) primary estrus sign: cow remains stationary when mounted; the cow makes no effort to escape when mounted by other cows. (2) Secondary estrus sign(s): mount, attempt to mount, anogenital sniff, and chin rest.

Detailed descriptions of behaviors are listed in Table 1. Estrus signs were recorded throughout the study period. Other social behavior was recorded during STE and nonestrus. For an event to be defined as a standing event, the mounted cow had to stand still and the mounting had to last for a minimum of $2 \mathrm{~s}$ (2 consecutive video pictures). Standing when mounted sideways or head-wise were also considered to be standing events. All first and last standing events, and the respective preceding and following mounts, were confirmed by one additional video observer. Other individual social behaviors (Mülleder et al., 2003) recorded included head butt, body butt, push away, chase up, threat, winner, avoid, play rub (head play and head rub), head lean, social lick, and rump lick.

In an attempt to give a clearer description of the behaviors, we modified the definition of the following behaviors, with the original authors and their definitions given in parentheses $(\mathbf{I}=$ initiator of the behavior; $\mathbf{R}=$ receiver of the behavior):

- Following: One cow chases another for more than $2 \mathrm{~m}$ without pushing (Pennington et al., 1986: one cow making a deliberate act to pursue another cow).

- Avoid: I avoids $\mathrm{R}$, although $\mathrm{R}$ does not visibly threaten I directly beforehand (Mülleder et al., 2003: I avoids R, although R does not threaten I directly beforehand).

- Rump lick: I licks rump region of R (Esslemont et al., 1980: licking back - licking of the back half of the recipient).

- Side mount: Mounting sideways with or without standing response (Esslemont et al., 1980: disoriented mounting - mounting head-to-side).

- Mounting: Mounting and succeeding in resting both legs on rump (Esslemont et al., 1980: mounting of another cow from behind). 
Table 1. Behaviors recorded

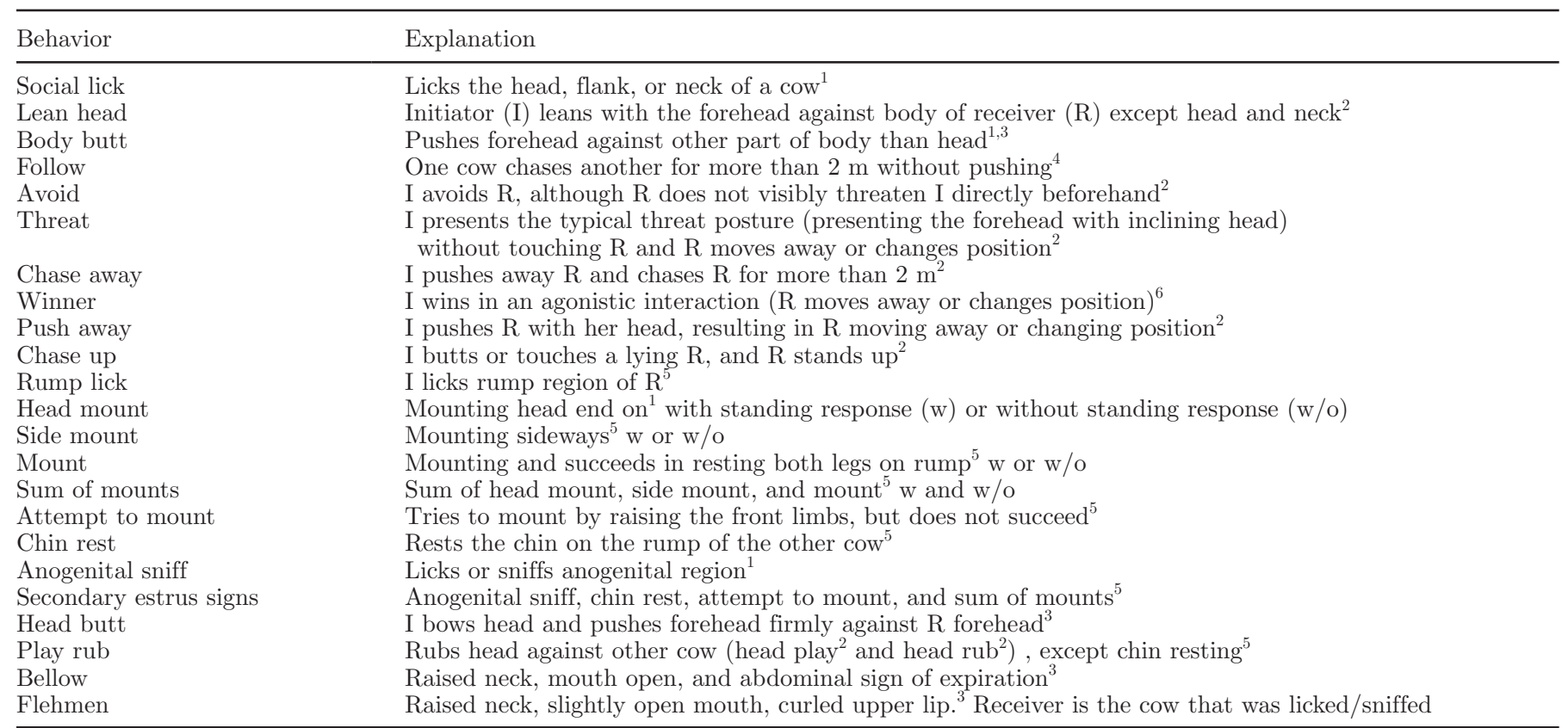

${ }^{1}$ Kerbrat and Disenhaus (2004).

${ }^{2}$ Mülleder et al. (2003). Modifications are described in Material and Methods.

${ }^{3}$ Keeling and Gonyou (2001).

${ }^{4}$ Pennington et al. (1986). Modifications are described in Material and Methods.

${ }^{5}$ Esslemont et al. (1980). Modifications are described in Material and Methods.

${ }^{6}$ Agonistic situations in which the behavior could not be clearly defined (differentiate between push away and threat).

- Attempt to mount: Tries to mount by raising the front limbs, but does not succeed (Esslemont et al., 1980: mounting attempts).

- Chin rest: Rests the chin on the rump of the other cow (Esslemont et al., 1980: chin-resting - resting of chin on the back half of the recipient).

- Play rub: Rubs head against other cow (head play and head rub), except chin resting (Mülleder et al., 2003: head rub -initiator rubs the head on receiver). Chin rest is not excluded in the latter definition of head rub.

- Chase up is defined as a cow butting a lying cow that stands up as a result of being butted (Mülleder et al., 2003). This was described earlier by Hurnik et al. (1975) as a cow alone in estrus tending to nudge resting cows in an effort to arouse them. In the present study the cows were observed approaching and then body butting or mounting lying cows that, as a result, stood up. It was difficult to differentiate between head play and head rub and therefore both were recorded as play rub. Head butt, body butt, push away, chase up, threat, win, and avoid were all regarded as agonistic behaviors (Mülleder et al., 2003). The identities of cows initiating and receiving individual behavior traits were recorded, except for flehmen, bellow, head butt, and play rub, as these either involved only one cow (flehmen and bellow) or could not be categorized (head butt and play rub).

Images were collected at the rate of 1 image/s and stored as JPEG files. Videos were analyzed retrospectively, using the program Axis Camera Control (Axis Communications), and the data were entered into a Microsoft Office Access database (Microsoft Corp., Redmond, WA). To avoid investigator bias, the researcher analyzing the video recordings had no knowledge of the estrous cycle stage of the individual animals.

\section{Statistical Analyses}

Associations between numbers of cows standing, milk yield, and parity (independent variables), and STE and estrus length were analyzed using multiple linear regression, with STE and estrus length, respectively, as dependent variables. The effect of parity on secondary estrus behaviors and social behaviors initiated or received was analyzed, using linear regression, with parity (primiparous vs. multiparous) as the independent variable. 
The mean frequency of behavioral signs, measured as counts per hour (cph), were calculated for the periods of the estrous cycle defined previously, and comparisons made between the cows with at least 2 standing events. Because the length of STE varied from cow to cow, the mean frequencies of signs were calculated in different ways. The mean frequencies during STE were first calculated as the total number of each behavior during STE divided by the total length of STE, where total means the sum over all cows with at least 2 standing events. This can be expressed as $\sum_{i} x_{i} / \sum_{i} t_{i}$, where $x_{i}$ is the number of a specific behavior during STE for the $i$ th cow and $t_{i}$ is the corresponding length of STE. We also calculated an alternative frequency mean as $1 / n \sum_{i} x_{i} / t_{i}$, where $n$ is the number of cows with at least 2 standing events. The 2 types of frequency means during STE gave similar results and only the first of these is reported.

The data consist of repeated measurements on each cow, such that observations within each cow are correlated, and simple formulas for the standard error of a mean cannot be used to calculate estimation uncertainties. Therefore, the uncertainties of the frequency estimates were calculated by a bootstrap procedure (Efron and Tibshirani, 1993), taking into account the repeated measurement design of the data. First, 10,000 bootstrap data sets were constructed by resampling, with replacement from the observed data set. Each cow, with all its associated measurements, was treated as one data unit in the resampling procedure, accounting for correlations between the measurements within a cow. Confidence intervals $(95 \%)$ and $P$-values were calculated by the bootstrap percentile method (Efron and Tibshirani, 1993). If the bootstrap replicates of the estimates contained duplicate values of zero (the null hypothesis), the $P$-value was not defined by the ordinary percentile method. In these cases, we computed it as the $P$-value corresponding to the shortest confidence interval not covering zero.

\section{RESULTS}

Based on progesterone measurements, 16 out of 20 cows were characterized as cyclic; STE was observed in 14 cows. The 2 remaining cycling cows expressed estrus signs other than standing behavior. One of the 14 cows in STE was excluded because the duration of her estrous cycle was $25 \mathrm{~d}$ and consequently observations for a full estrus were incomplete. Of the remaining 13 cows in STE, 2 cows had only one standing event and thus other estrus signs could not be described during

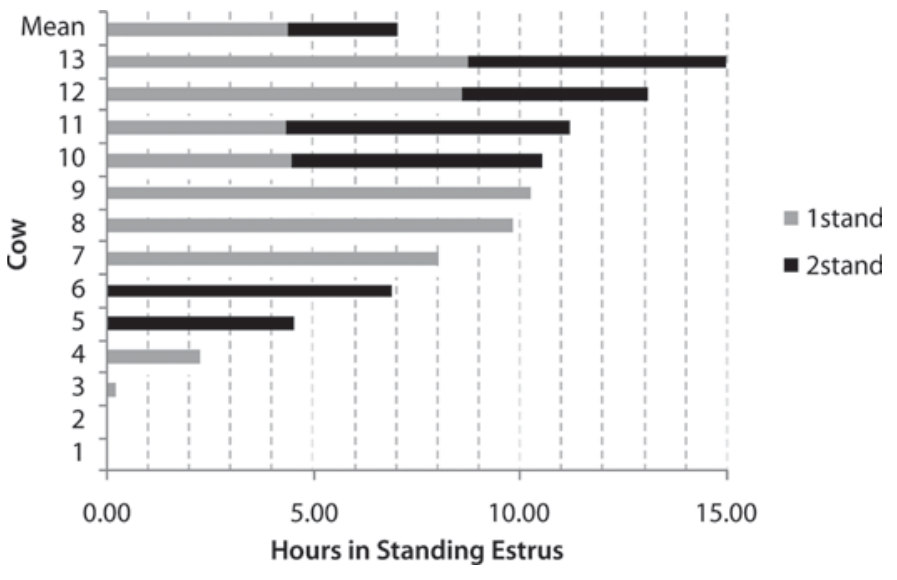

Figure 1. Duration of individual standing estrus (STE; cows 1 to 13) and number of cows in heat during STE of 13 Holstein-Friesian cows. 1stand $=1$ cow in STE at a time; 2 stand $=2$ cows in STE at a time.

STE. Standing estrus was observed during $15 \%$ of the study period ( 81 of $528 \mathrm{~h}$ ). In this period, cows were alone in STE for $65 \%$ of the time (Figure 1). The 13 cows in STE had a 305-d mean milk yield of 6,016 \pm $336.2 \mathrm{~kg}( \pm \mathrm{SE})$. Their mean BCS was $3.02 \pm 0.044$, BCS change of $-0.02 \pm 0.053$, and mean BW change of $-2.35( \pm 4.233) \mathrm{kg}$ during the study period.

\section{Duration of STE and Mounting Estrus}

The mean duration of STE and mounting estrus was $7.1 \pm 1.44 \mathrm{~h}(\mathrm{n}=13$; Figure 1$)$ and $12.9 \pm 1.84 \mathrm{~h}$, respectively. The estrus period started, on average, $4.3 \pm$ $2.06 \mathrm{~h}$ before STE and ended $2.0 \pm 0.60 \mathrm{~h}$ after the last standing event. If cows that showed standing behavior only once were excluded $(\mathrm{n}=2)$, the mean STE length was $8.4 \pm 1.36 \mathrm{~h}(\mathrm{n}=11)$ with an estrus duration of $13.0 \pm 1.44 \mathrm{~h}(\mathrm{n}=11)$. The 2 cyclic cows without recorded standing events participated in few mounting interactions (a total of 2 initiated and 3 received) and duration of mounting estrus could not be estimated. No significant relationship was found between stand duration, parity, milk yield, or number of cows in estrus.

\section{Behavior During STE}

The total number of standing events during STE averaged $17.4 \pm 4.05(\mathrm{n}=13)$ and $21.5 \pm 4.15(\mathrm{n}=11)$ per cow with a mean frequency of $2.6 \pm 0.43 \mathrm{cph}(\mathrm{n}=$ 11). Standing behavior, as a response to being mounted sideways and head-wise, occurred in 2 cows 10 times out of a total of 223 standing events.

The frequencies of initiated and received behaviors (Table 1) of cows expressing more than one standing 
event $(\mathrm{n}=11)$ during the periods STE and nonestrus are described in Figure 2. No significant effect of parity on secondary estrus signs and social behaviors initiated or received was observed between primiparous and multiparous cows. Neither mount nor attempt to mount was observed in any cows during nonestrus. Three of 11 cows did not mount during STE. Mounting accounted for only $2.2 \mathrm{cph}$ initiated and 1.7 mounts without standing response received during STE (Table 2). Received disoriented mounts (head-wise and sideways) were at low frequencies, but were significantly associated with STE (Table 2). Anogenital sniffing and chin resting behaviors were observed in all cows and most frequently expressed during STE (Table 2). Only 4 cows expressed any of these signs during nonestrus. The sum of initiating secondary estrus signs was numerically greater than that of receiving during STE, and all single secondary estrus signs occurred at higher frequencies during STE compared with nonestrus (Table 2).

\section{Social and Agonistic Behavior}

All 11 cows were involved in social and agonistic behavior during STE and nonestrus, but the frequency of the different signs differed between the 2 periods. Greater frequencies were observed in some social behaviors initiated (chase up, head butt, play rub, follow, flehmen, avoid, bellow) and received (push away, threat, social lick), suggesting an importance of these signs during STE (Figure 2). Chase up and head butt were observed at relatively high frequencies during STE, but the remaining social behaviors occurred infrequently (Table 2). Push away was the only behavior expressed more intensively during nonestrus than during STE (Table 2).

\section{Effect of Number of Cows in Standing Estrus}

The effect of number of cows in estrus on frequency of behaviors in STE was analyzed. Cows that were in STE simultaneously initiated and received approximately double frequencies of secondary estrus signs compared with cows that were alone in STE (Table 3). Mounts initiated represented the major difference between these 2 groups ( 4.6 vs. $0.5 \mathrm{cph}$ ). Other behaviors that differed significantly between the 2 groups, but occurred at lower frequencies, were attempt to mount received (Table 3 ), avoid (0.03 vs. $0.11 ; P<0.001$ ), and threat initiated ( 0 vs. $0.05 ; P=0.02$ ). Rump lick was only observed in cows alone in heat, but was not significantly associated with STE. No significant differences were observed between the 2 groups in the agonistic and secondary estrus signs chase up, head butt, chin rest received, anogenital sniff, and attempt to mount initiated.

\section{Behavioral Changes Around Standing Estrus}

The frequencies of secondary estrus signs at specific stages in the estrous cycle are presented in Figure 3. Secondary estrus signs changed significantly from nonestrus compared with the periods $24 \mathrm{~h}$ before, during, and after STE. In other phases of the estrous cycle, secondary estrus signs occurred infrequently, at the same level as during nonestrus and with no obvious pattern. Initiating secondary estrus signs increased gradually during the 24-h period before STE (Figure 3 ); anogenital sniffing, chin resting, and attempt to mount accounted for most behaviors expressed in this period. A significant increase occurred in secondary estrus signs initiated from the period 4 to $6 \mathrm{~h}$ before STE to 1 to $3 \mathrm{~h}$ before STE (3.3 and $7.6 \mathrm{cph}$, respectively), and a decrease from STE compared with 1 to $3 \mathrm{~h}$ postSTE (11.2 and $2.3 \mathrm{cph}$, respectively), but no differences were observed between periods 1 to $3 \mathrm{~h}$ before STE and STE (Table 4). Significantly more total mounts were initiated during STE (mean 2.2) compared with 1 to 3 $\mathrm{h}$ before STE (mean 0.9 ) and 1 to $3 \mathrm{~h}$ post-STE (mean 0.3 ; Table 4).

A significant increase was observed in secondary estrus signs received between 1 to $3 \mathrm{~h}$ before STE and during STE (means of 2.2 and $8.4 \mathrm{cph}$, respectively; Table 4). Compared with STE, the period 1 to $3 \mathrm{~h}$ post-STE was characterized by significantly lower incidences of secondary estrus signs and mounts (Table 4). Initiated and received secondary estrus signs were 2.3 and $1.5 \mathrm{cph}$, respectively, during the period 1 to 3 $\mathrm{h}$ post-STE (Table 4). The differences between initiated and received SEC was most prominent during the period 1 to $3 \mathrm{~h}$ before STE.

Cows with a single stand event $(\mathrm{n}=2)$ and short stand duration of $<3 \mathrm{~h}(\mathrm{n}=2)$ did not compensate with high frequencies of mounts around STE. However, they initiated high frequencies of other secondary estrus signs (a total of 234 vs. 3 mounts initiated) in the last $6 \mathrm{~h}$ before STE. Cycling cows with no stand events (n $=2$ ) initiated 1 and received only 3 mounts altogether during the $22 \mathrm{~d}$ of the study.

\section{Behavior During Luteal Stage and Behavior of Acyclic Cows}

Only minor differences were observed in frequency of secondary estrus signs between the periods nonestrus and the luteal phase ( 7 to 16). Mounting was not observed during nonestrus, whereas a mean frequency 


\section{Behaviors initiating}

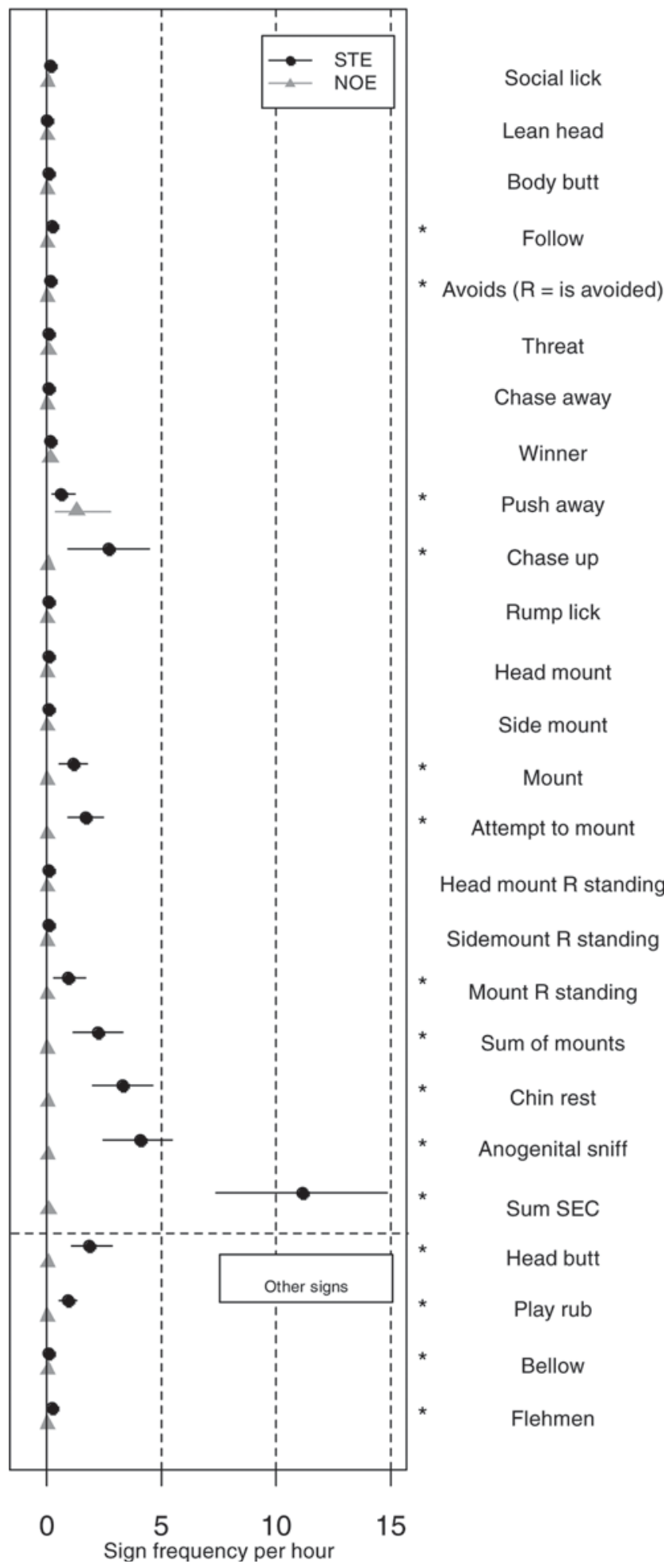

\section{Behaviors receiving}

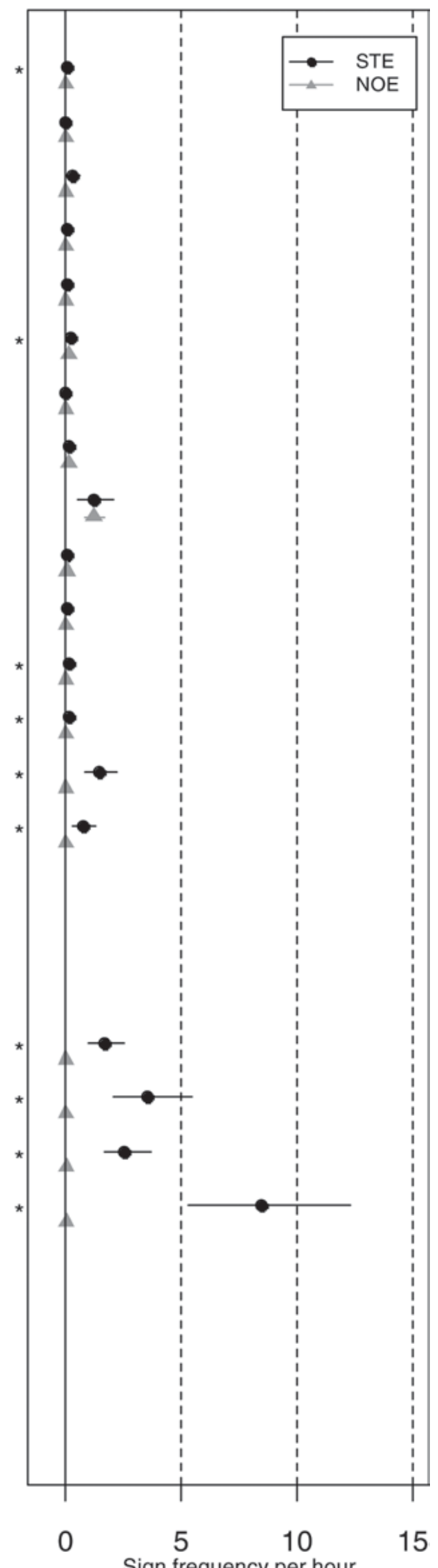

Figure 2. Estimates of expected frequency (counts per hour) of behaviors initiated and received with 95\% confidence intervals during standing estrus (STE, - ) and day in which none of the cows were in estrus (NOE, $\mathbf{\Delta}$ ). The left panel displays initiating behaviors, with other signs (neither initiating nor receiving) below the dashed line. The right panel displays receiving behaviors: mount $=$ mount with no standing response; $\mathrm{R}$ standing = mount with standing response of receiver; SEC = secondary estrus signs (anogenital sniff, chin rest, attempt to mount, and sum of mounts); other signs $=$ only one cow involved or mutual behaviors. ${ }^{*}$ Means between STE and NOE differ significantly $(P<0.05)$. 
of $0.03 \pm 0.000 \mathrm{cph}$ initiated was found in the luteal phase. No cows stood to be mounted during the luteal phase. All 11 cows contributed to secondary estrus signs initiated and received with means of $0.1 \pm 0.00$ and $0.1 \pm 0.00 \mathrm{cph}$, respectively, during luteal phase. The 4 acyclic cows initiated a total of 84 estrus signs during the 22-d study period, and 58 of these (69\%) were interactions with cows in STE, of which 11 were mounts. Only 2 and 4 signs were directed toward other acyclic cows and cows in luteal phase, respectively. The 4 acyclic cows received 112 estrus signs during the 22-d study period. Only 8 were mounts and all were initiated by cows in STE.

\section{Estrus Stages of Cows in Mounting Interactions}

The stages in the estrous cycle of initiators and receivers of all mounts were investigated. Among the

Table 2. Behaviors during standing estrus (STE) and a selected day of no cows in estrus (NOE)

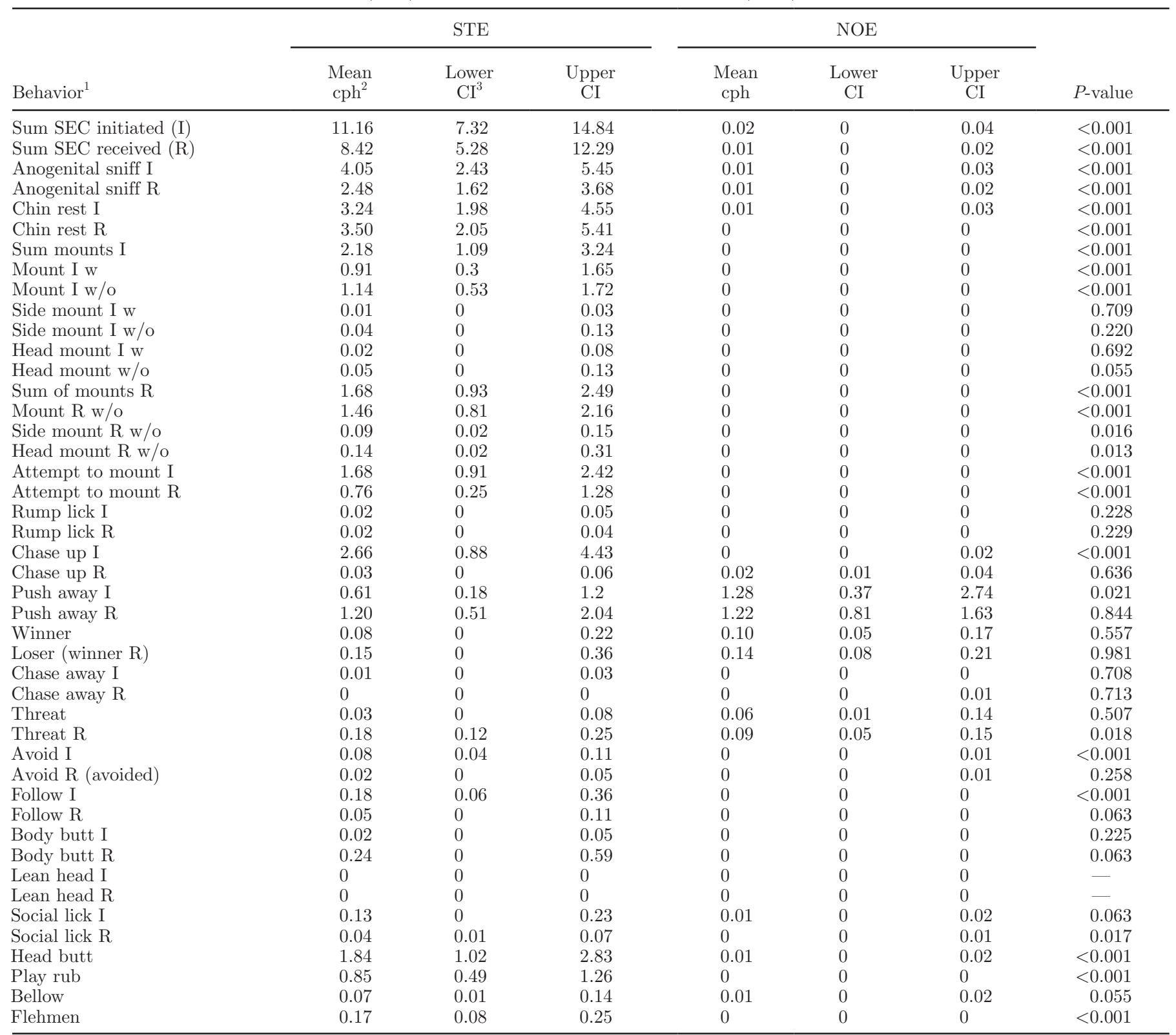

${ }^{1} \mathrm{SEC}=$ secondary estrus signs (anogenital sniff, chin rest, mount, and attempt to mount); $\mathrm{w}=$ with standing reaction of receiver; $\mathrm{w} / \mathrm{o}=\mathrm{without}$ standing reaction of receiver.

${ }^{2} \mathrm{cph}=$ counts per hour.

${ }^{3} \mathrm{CI}=95 \%$ CI. 
Table 3. Secondary estrus signs (SEC) and number of cows in standing estrus (STE)

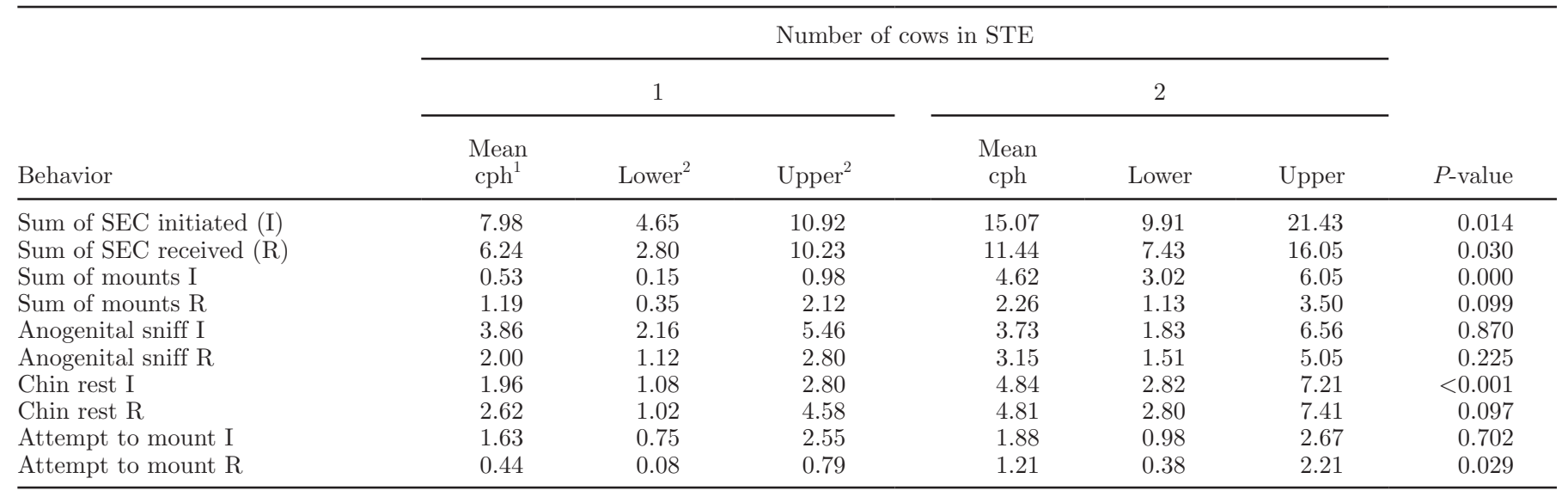

${ }^{1} \mathrm{cph}=$ counts per hour.

${ }^{2}$ Lower/Upper $=$ lower/upper limit of $95 \%$ CI of period.

479 mounts recorded during the 22 -d study period, all involved at least one cow in STE $(98.5 \%)$ or within 4 $\mathrm{h}$ of STE $(1.5 \%)$. No cows were mounted during the last 24-h period before STE. During periods in which 2 cows were in STE, 87 of $112(77 \%)$ of all mounts with standing responses were interactions between these 2 cows. During periods of only 1 cow in STE, 23 of 127 $(18 \%)$ of mounts with standing responses were initiated by cows within $24 \mathrm{~h}$ before their own STE. In only one event $(0.01 \%)$ was the mounting cow within $24 \mathrm{~h}$ after her own STE, and 45 of 127 (35\%) standing events were mounts by cows in the luteal phase.

Luteal cows were only mounted by cows in STE (6 mounts) and cows within $24 \mathrm{~h}$ pre-stand (1 mount). Mounts initiated by cows in the luteal phase were predominantly directed toward cows in STE (78 of 84; 93\%) and particularly toward cows alone (75 of $84 ; 89 \%$ ) in STE. The remaining 6 mounts $(7 \%)$ were received by cows within 6 h post-STE. The 2 cycling cows that did not express STE were involved in mounting interactions on only 5 occasions during the study period. The 2 cows expressing only a single stand event and the 2 cows with the shortest STE $(0.3$ and $2.3 \mathrm{~h})$ were involved in only 13 mounting interactions during estrus (mount period). Disoriented mounting (head-wise or sideways mounting) always involved a cow within $12 \mathrm{~h}$ before, or during, STE.

\section{DISCUSSION}

Major differences in numerous behaviors throughout the estrous cycle are described in this study. Effects of milk yield and flooring on sexual behavior is well documented in the literature (Phillips and Schofield, 1990; Lopez et al., 2004). The present data provide information on sexual behavior that is more or less unrelated to the suppressing effect of high milk yield and concrete floors. Other studies have compared signs during estrus with signs during periods in proximity to estrus or during the luteal phase (Hurnik et al., 1975; Kerbrat and Disenhaus, 2004). In those studies, cows in estrus may have interacted with nonestrous cows. It could be beneficial to compare behavior associated with estrus with behavior during a control period at other stages, not influenced by other cows in estrus. This has been accomplished in our study in which comparisons are made with day nonestrus.

\section{Durations of STE and Mounting Estrus}

In the present study, HF cows expressed short STE with variable, low mounting frequencies, despite being moderate-yielding cows in good nutrition and held in an outdoor pad with soft flooring. Duration of STE in dairy cows is traditionally considered to be approximately 18 h (Hammond, 1927; Trimberger, 1948). Our results, in which the mean duration of STE and estrus were shorter, concur with the results from other continuous studies (Hurnik et al., 1975; Rodtian et al., 1996) and are supported by results from larger studies using HeatWatch (Dransfield et al., 1998; At-Taras and Spahr, 2001) or visual observations (Yoshida and Nakao, 2005). In agreement with the present study, Lopez et al., (2004) reported that $15 \%$ of estruses (57 of 380) consisted of only one standing event and these short STE cows could easily be missed in noncontinuous studies.

\section{Behavior During STE}

Total standing and mounting events reported in this study were considerably higher than in other continuous 

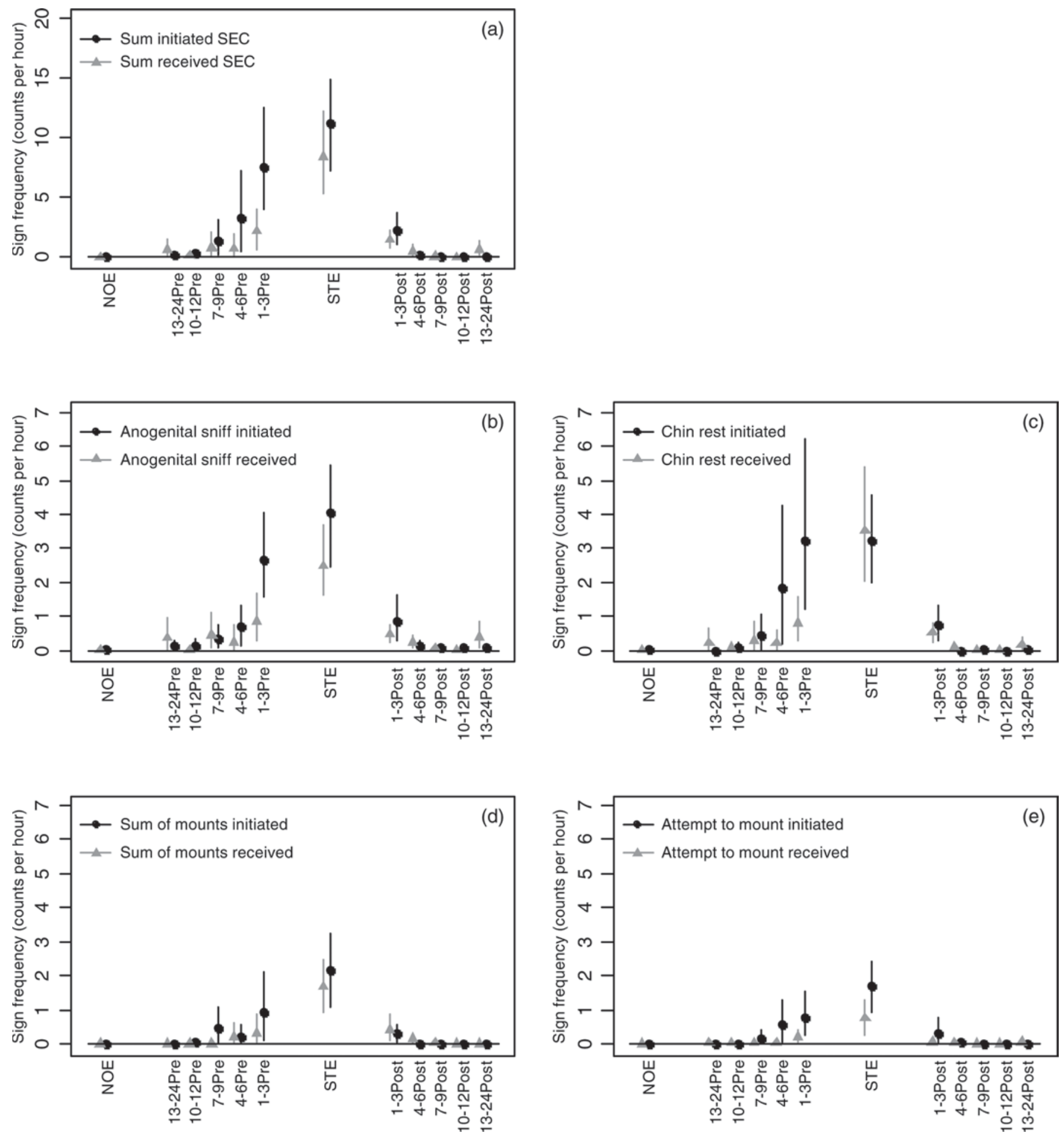

Figure 3. Estimates of expected frequency (counts per hour) of secondary estrus signs (a, b, c, d, e) with $95 \%$ CI initiated (•) and received $(\boldsymbol{\Delta})$ at specific stages of estrous cycle. SEC $=$ secondary estrus signs (anogenital sniff, chin rest, mount, and attempt to mount); NOE $=$ selected day of none in estrus; Pre = hour interval before STE; STE = standing estrus; Post = hour interval after STE. 
Table 4. Comparison of secondary estrus signs (SEC) between periods ${ }^{1}$ around standing estrus (STE)

\begin{tabular}{|c|c|c|c|c|c|c|c|c|c|}
\hline Period 1 & Period 2 & Sign & \multicolumn{3}{|c|}{ Period 1} & \multicolumn{3}{|c|}{ Period 2} & $P$-value 2 \\
\hline 1-3 Pre & 4-6 Pre & Sum SEC received $(\mathrm{R})$ & 2.18 & 0.67 & 4.09 & 0.70 & 0 & 2.00 & $<0.001$ \\
\hline 1-3 Pre & 4-6 Pre & Sum of mounts I & 0.91 & 0.09 & 2.15 & 0.21 & 0 & 0.61 & 0.016 \\
\hline 1-3 Pre & 4-6 Pre & Sum of mounts R & 0.30 & 0 & 0.85 & 0.21 & 0 & 0.58 & 0.708 \\
\hline STE & 1-3 Pre & Sum of mounts I & 2.18 & 1.10 & 3.23 & 0.91 & 0.09 & 2.15 & 0.021 \\
\hline STE & 1-3 Pre & Sum of mounts $\mathrm{R}$ & 1.68 & 0.95 & 2.49 & 0.30 & 0 & 0.85 & $<0.001$ \\
\hline STE & 1-3 Post $^{8}$ & Sum SEC I & 11.16 & 7.27 & 14.90 & 2.27 & 1.00 & 3.76 & $<0.001$ \\
\hline STE & 1-3 Post & Sum SEC R & 8.42 & 5.33 & 12.21 & 1.48 & 0.82 & 2.21 & $<0.001$ \\
\hline STE & 1-3 Post & Sum of mounts I & 2.18 & 1.10 & 3.23 & 0.30 & 0.06 & 0.55 & $<0.001$ \\
\hline STE & 1-3 Post & Sum of mounts R & 1.68 & 0.95 & 2.49 & 0.42 & 0.09 & 0.88 & $<0.001$ \\
\hline
\end{tabular}

${ }^{1}$ Periods 1 and 2 of compared periods.

${ }^{2} P$-value for the test of difference between period 1 and 2 .

${ }^{3} \mathrm{cph}=$ counts per hour.

${ }^{4}$ Lower/Upper $=$ lower/upper limit of $95 \%$ CI of period.

${ }^{5} 1-3$ Pre $=$ the period 1 to $3 \mathrm{~h}$ before STE.

${ }^{6} 4-6$ Pre $=$ the period 4 to $6 \mathrm{~h}$ before STE.

${ }^{7} \mathrm{SEC}=$ anogenital sniff, chin rest, mount, and attempt to mount.

${ }^{8} 1-3$ Post $=$ the period 1 to $3 \mathrm{~h}$ post-STE.

studies (Rodtian et al., 1996; Kerbrat and Disenhaus, 2004), but lower than reported in the older study of Esslemont and Bryant (1976). This apparent decrease in total mounting activity in recent years is supported by data published by Dransfield et al. (1998). Frequencies per hour were not reported in these studies but are relevant in visual heat detection. The higher total mounting activity reported in the present study, as compared with previous studies, could be due to one or a combination of various positive factors, including spontaneous estruses (Walton et al., 1987), soft flooring (Phillips and Schofield, 1990), moderate milk yield (Lopez et al., 2004), or good BCS (Pennington et al., 1986), as these have all been described previously as affecting estrus expression. Nevertheless, mounting was not a consistent sign of all cows in STE in the current study. Cows with an absence, or short duration, of STE also expressed low mounting activity around STE, as previously noted by Van Vliet and van Eerdenburg (1996). The results from our study suggest that heat detection based on mounting activity can be a challenge, even in herds in which potentially negative influences have been reduced.

To assist with the visual detection of estrus, we can distinguish between behaviors that occur only during estrus and those that increase in frequency during estrus. The former are a clearer indicator of estrus, but the latter are more likely to be observed. As previously reported from other studies (Esslemont et al., 1980; Kerbrat and Disenhaus, 2004), our study indicated a higher frequency and prevalence of behaviors other than mounting, during both STE and nonestrus. As anogenital sniffing and chin resting are sometimes performed in the nonestrous state, they are less predictive of estrus than mounting (Phillips and Schofield, 1990). However, identifying repeated incidences (high intensity) of these signs would assist in distinguishing between estrous and nonestrous cows in visual heat detection. The increase in intensity of these signs before STE, and persistence after STE, was previously reported by Esslemont et al. (1980). In addition to these, the social and agonistic behaviors chase up initiated, head butt, play rub, push away received, following, threat received (being threatened), flehmen, avoid, bellow, and social lick increased significantly, whereas push away initiated decreased during STE. Few other studies report estrus affecting social and agonistic interactions (Hurnik et al., 1975; Phillips and Schofield, 1990; Kerbrat and Disenhaus, 2004). Rump lick, following, and chase up have not previously been described as being associated with STE. Some behaviors (threat received, social lick, flehmen, avoid, and bellow) occurred at low rates $(<0.2$ $\mathrm{cph}$ ) and are consequently of less practical use for heat detection. Increased threat received during STE could be due to proactive cows in heat disturbing other cows. Head butt and play rub are frequent and characteristic signs involving head and neck caressing. These signs were observed to be of longer duration (minutes) than the traditional secondary estrus signs and are therefore easier to detect. Hurnik et al. (1975) described how a 
cow alone in estrus tended to nudge resting cows in an effort to arouse them. This is probably the same sign that we recorded as chase up, although it has not been quantified in relation to estrus in previous studies. The present data suggest that chase up can be regarded as an estrus sign.

\section{Number of Cows in STE and Behavioral Signs}

Considerable evidence exists in the literature, and from the present study, that mounting behavior increases when more cows are in estrus (Hurnik et al., 1975; Roelofs et al., 2005). However, these data contrast with those of Pennington et al. (1986), who reported that the number of cows in estrus was not positively associated with activities initiated. This difference could be due to differences between the studies, such as floor types or the method of weighting according to hours in STE.

\section{Behavioral Changes Around STE}

The present data, supported by those reported by Kerbrat and Disenhaus (2004), show significant increases in initiating (proceptive) behaviors during the $24 \mathrm{~h}$ before STE. Our data suggest that behavioral changes can serve as predictors of specific stages of estrus. This concept has not been thoroughly described in the literature previously. Mounting activity can easily be overlooked, and thus the beginning and end of estrus period missed (Hurnik et al., 1975). We suggest that for visual heat detection, it may be better to consider the sum of secondary estrus signs rather than the individual sign. This hypothesis is supported by the data presented by van Eerdenburg et al. (1996) and Kerbrat and Disenhaus (2004). The gradual increase in levels of initiated secondary estrus signs before STE (Figure 3) is also reported by Esslemont et al. (1980). Nevertheless, our data revealed the increase and the high frequencies of secondary estrus signs initiated closer to STE (9 and $3 \mathrm{~h}$, respectively) compared with Esslemont et al. (1980; 24 and $12 \mathrm{~h}$, respectively), indicating a decrease in pre-stand activity in HF over the last decades.

The significant proceptivity, reflected by the changes in initiating behavior between periods 4 to $6 \mathrm{~h}$ and 1 to $3 \mathrm{~h}$ before STE, could be used as an indicator for the start of the estrus period, in agreement with the study of Kerbrat and Disenhaus (2004). Unlike with initiated behavior, receptive behaviors (received secondary estrus signs) were first observed at high frequencies when STE was identified, as described previously by Esslemont et al. (1980) and Pennington et al. (1986). We suggest the differences in initiated and received behaviors throughout estrus as a topic for future research. The receptivity of the estrous cow depends on interactions with other (initiating) cows and the willingness of the cow itself to receive attention. This social dependence and specificity of receptive behavior to the short STE period may partly explain some of the individual differences in expression of estrus. We suggest that the profound receptivity of secondary estrus signs during STE could be a practical tool for identifying STE.

The end of estrus was identified by a sudden decrease in both initiated and received estrus signs immediately after the standing period. According to other studies (Dransfield et al., 1998; Nebel et al., 2000; Roelofs et al., 2004), the post-STE or preovulatory period indicates the start of an optimal time window for AI. The observed "turn off" in estrus signs, the first hours poststand, is indicative of the post-STE period.

\section{Estrus Stage of Cows in Mounting Interactions}

Our data indicate that cows simultaneously in estrus prefer mounting each other rather than cows not in estrus. As previously reported in other studies, our study indicated that expression of mounting was strongly associated with one of the involved cows being in estrus (Hurnik et al., 1975; Van Vliet and van Eerdenburg, 1996).

\section{Behavior in Luteal Stage and in Acyclic Cows}

Acyclic cows and luteal cows were themselves not sexually active, but received attention from cows in STE. The frequency of secondary estrus signs during nonestrus was very low, indicating that cows in estrus is a prerequisite of these behaviors.

\section{CONCLUSIONS}

Our detailed observations of HF cows, made throughout complete cycles of estrus, indicate that chase up should be regarded as a sign of estrus and that changes in proceptive and receptive behaviors could be used to assess stages in estrus. Increased initiated secondary estrus signs during the 6-h period before STE (proceptivity) could act as a warning of STE in visual heat detection, whereas the profound increase in received behavior (receptivity) could be used as a practical tool to identify the start of STE. We suggest that the significant decrease in all behavior during the first 3 $\mathrm{h}$ post-STE could be used to identify the post-stand period. The various behavioral changes identified in this study may improve heat detection, and therefore increase pregnancy rates, in dairy farms. 


\section{ACKNOWLEDGMENTS}

The authors gratefully acknowledge the contributions of Noel Byrne and the staff at Ballydague farm (Teagasc, Morrepark, Fermoy, Ireland) for their care of the animals and help with this study. We thank Jostein Rudi, Timotei Data (Ringebu, Norway), for technical support with video recording, Ellen Dahl at the Norwegian School of Veterinary Science (Oslo, Norway) for laboratory assistance, Jørund Hage at the National Institute of Nutrition and Seafood Research (Bergen, Norway) for help with data handling, and Lucy Robertson (Skedsmokorset, Norway) for English suggestions. Support for the preparation of the antiprogesterone monoclonal antibody and the progesterone peroxidase conjugate was provided by the Estonian Science Foundation (Tallinn, Estonia). The study was funded by the Norwegian Research Council projects "Oestrus and Oestrus Behaviour in NRF and Holstein Breeds in Modern Cattle Housing Systems" (173974/I10) and "Modern Application Driven Statistical Challenges" (186951/I30).

\section{REFERENCES}

At-Taras, E. E., and S. L. Spahr. 2001. Detection and characterization of estrus in dairy cattle with an electronic heatmount detector and an electronic activity tag. J. Dairy Sci. 84:792-798.

Dransfield, M. B., R. L. Nebel, R. E. Pearson, and L. D. Warnick. 1998. Timing of insemination for dairy cows identified in estrus by a radiotelemetric estrus detection system. J. Dairy Sci. 81:18741882.

Efron, B., and R. Tibshirani. 1993. An Introduction to the Bootstrap. Chapman \& Hall/CRC, Boca Raton, FL.

Esslemont, R. J., and M. J. Bryant. 1976. Oestrous behavior in a herd of dairy cows. Vet. Rec. 99:472-475.

Esslemont, R. J., R. G. Glencross, M. J. Bryant, and G. S. Pope. 1980. A quantitative study of pre-ovulatory behavior in cattle (British Friesian heifers). Appl. Anim. Ethol. 6:1-17.

Foote, R. H. 1975. Estrus detection and estrus detection aids. J. Dairy Sci. $58: 248-256$.

Hammond, J. 1927. The Physiology of Reproduction in the Cow. Cambridge University Press, Cambridge, UK.

Hurnik, J. F., G. J. King, and H. A. Robertson. 1975. Estrous and related behavior in postpartum Holstein cows. Appl. Anim. Ethol. $2: 55-68$.

Keeling, L. J., and H. W. Gonyou. 2001. Social behaviour in farm animals. Pages 113-145 in The Social Behaviour of Cattle. M.-F. Bouissou, A. Boissy, P. L. Neindre and I. Veissier, ed. CAB International, Wallingford, UK.

Kerbrat, S., and C. Disenhaus. 2004. A proposition for an updated behavioral characterisation of the oestrus period in dairy cows. Appl. Anim. Behav. Sci. 87:223-238.

Lopez, H., L. D. Satter, and M. C. Wiltbank. 2004. Relationship between level of milk production and estrous behavior of lactating dairy cows. Anim. Reprod. Sci. 81:209-223.
Lowman, B. G., N. Scott, and S. Somerville. 1976. Condition Scoring of Cattle. Rev. ed. Bulletin no. 6. East of Scotland College of Agriculture, Edinburgh, UK.

Mülleder, C., P. Palme, C. Menke, and S. Waiblinger. 2003. Individual differences in behavior and in adrenocortical activity in beef-suckler cows. Appl. Anim. Behav. Sci. 84:167-183.

Nebel, R. L., M. G. Dransfield, S. M. Jobst, and J. H. Bame. 2000. Automated electronic systems for the detection of oestrus and timing of AI in cattle. Anim. Reprod. Sci. 60-61:713-723.

O'Driscoll, K., A. Hanlon, and L. Boyle. 2008. The effect of out-wintering pad design on the synchrony of dairy cow behavior. J. Dairy Sci. 91:4651-4660.

Pennington, J. A., J. L. Albright, and C. J. Callahan. 1986. Relationships of sexual activities in estrous cows to different frequencies of observation and pedometer measurements. J. Dairy Sci. 69:2925-2934

Phillips, C. J. C., and S. A. Schofield. 1990. The effect of environment and stage of the oestrous cycle on the behaviour of dairy cows. Appl. Anim. Behav. Sci. 27:21-31.

Rodtian, P., G. King, S. Subrod, and P. Pongpiachan. 1996. Oestrous behaviour of Holstein cows during cooler and hotter tropical seasons. Anim. Reprod. Sci. 45:47-58.

Roelofs, J. B., E. G. Bouwman, S. J. Dieleman, F. J. C. M. van Eerdenburg, L. M. T. E. Kaal-Lansbergen, N. M. Soede, and B. Kemp. 2004. Influence of repeated rectal ultrasound examinations on hormone profiles and behaviour around oestrus and ovulation in dairy cattle. Theriogenology 62:1337-1352.

Roelofs, J. B., F. J. van Eerdenburg, N. M. Soede, and B. Kemp. 2005. Various behavioral signs of estrous and their relationship with time of ovulation in dairy cattle. Theriogenology 63:1366-1377.

Sprecher, D. J., D. E. Hostetler, and J. B. Kaneene. 1997. A lameness scoring system that uses posture and gait to predict dairy cattle reproductive performance. Theriogenology 47:1179-1187.

Stevenson, J. S., M. K. Schmidt, and E. P. Call. 1983. Factors affecting reproductive performance of dairy cows first inseminated after five weeks postpartum. J. Dairy Sci. 66:1148-1154.

Trimberger, W. T. 1948. Breeding efficiency in dairy cattle from artificial insemination at various intervals before and after ovulation. Univ. Nebraska Ag. Exp. Sta. Res. Bull. 153:3-25.

Van Eerdenburg, F. J. C. M., S. H. Loeffler, and J. H. van Vliet. 1996. Detection of oestrus in dairy cows: A new approach to an old problem. Vet. Q. 18:52-54.

Van Vliet, J. H., and F. J. C. M. van Eerdenburg. 1996. Sexual activities and oestrus detection in lactating Holstein cows. Appl. Anim. Behav. Sci. 50:57-69.

Waldmann, A. 1993. Enzyme immunoassay (EIA) for milk progesterone using a monoclonal antibody. Anim. Reprod. Sci. 34:19-30.

Waldmann, A. 1999. Monoclonal antibodies to progesterone: Characterization and selection for enzyme immunoassay in bovine milk. Hybridoma 18:289-296.

Walton, J. S., L. P. Veenhuizen, and G. J. King. 1987. Relationships between time of day, estrous behavior, and the preovulatory luteinizing hormone surge in Holstein cows after treatment with cloprostenol. J. Dairy Sci. 70:1652-1663.

Williamson, N. B., R. S. Morris, D. C. Blood, and C. M. Cannon. 1972. A study of oestrous behaviour and oestrus detection methods in a large commercial dairy herd. I. The relative efficiency of methods of estrus detection. Vet. Rec. 91:50-58.

Yoshida, C., and T. Nakao. 2005. Some characteristics of primary and secondary oestrous signs in high-producing dairy cows. Reprod. Domest. Anim. 40:150-155. 